\title{
Amoebae as Genitors and Reservoirs of Giant Viruses
}

\author{
Didier Raoult Mickael Boyer \\ URMITE CNRS IRD UMR 6236, Faculté de Médecine, Unité des Rickettsies, Marseille, France
}

\section{Key Words}

Amoeba - Giant viruses - Marseillevirus - Mimiviruses

Phagocytic protist $\cdot$ Rhizome of life $\cdot$ Virophage

\begin{abstract}
Amoebae are unicellular phagocytes that feed on microorganisms in their environment. Some amoebae have the largest genome size currently known on earth. They phagocytose any inert particle larger than $0.5 \mu \mathrm{m}$. Phagocytic amoebae can harbor different bacteria, fungi and giant viruses within the same cell. There is evidence of lateral gene transfer between the amoeba and its microbiological hosts. There is also evidence of gene exchange between viruses and bacteria hosted in amoebae. Moreover, there is evidence of gene transfer between viruses, such as Mimivirus and the virophage. As a consequence, viruses and intracellular bacteria living in amoebae have a sympatric lifestyle and large chimeric genome repertoires. We conclude that phagocytic protists continuously generate new species with chimeric repertoires that may succeed later if adapted to the environmental conditions and selected in a specific niche.
\end{abstract}

Copyright $\odot 2010$ S. Karger AG, Basel

\section{Introduction}

We recently described Mimivirus and Mamavirus, whose size and genomic contents were comparable to those of bacteria [1-3]. These viruses were isolated from amoebae. Mimivirus has a genome of $1.2 \mathrm{Mb}$ and a phys- ical size comparable to that of small bacteria [4]. This virus of amoeba did not remain a unique discovery. Indeed, it was followed by the discovery of a virus of the same species, but with a slightly larger genome, Mamavirus, and that of a parasitic virus of these giant viruses, the virophage $[3,5]$. We also identified another giant virus, Marseillevirus [6], and new isolated giant viruses are currently under characterization in our laboratory [7]. In this article, we wish to show that it is not by chance that amoebae are associated with the giant viruses and that many giant viruses could be identified by co-cultures of amoebae.

\section{Amoebae as Phagocytic Protists}

Amoebae are phagocytic protists that can be considered to be wild macrophages [8]. They have the capacity to phagocytose particles of a size greater than $0.5 \mu \mathrm{m}$ (fig. 1) [9] and, in fact, will engulf any object larger than this size - including latex beads. Therefore, they do not need to recognize specific markers on microorganisms to ingest them. Free-living amoebae can be found in all environments (e.g. in water, on the ground) and also in larger organisms, such as humans. Amoebae have a behavior pattern that probably approaches that of archaeal protists, also named protoeukaryotes [10]. They can phagocytose and be infected by several microorganisms at the same time (fig. 2) [6], and they have variable relationships with these microorganisms [8]. In some cases, the microorganism becomes prey for the amoebae, which feed on surrounding microorganisms, in particular, bacteria. In

\section{KARGER}

Fax +4161306 1234

E-Mail karger@karger.ch

www.karger.com
(C) 2010 S. Karger AG, Basel

$0300-5526 / 10 / 0535-0321 \$ 26.00 / 0$

Accessible online at:

www.karger.com/int
Didier Raoult

URMITE CNRS IRD UMR 6236, Faculté de Médecine

Unité des Rickettsies, 27 Bd Jean Moulin

FR-13385 Marseille (France)

Tel. +33 49132 4376, Fax +33 49138 7772, E-Mail didier.raoult@gmail.com 


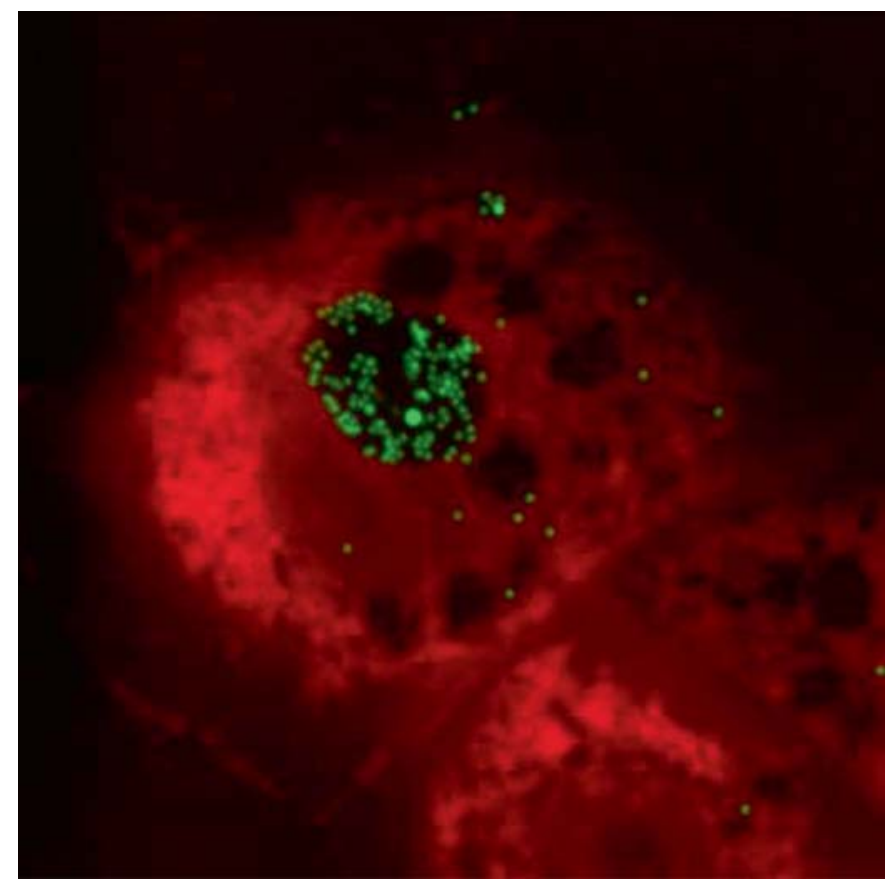

Fig. 1. Confocal laser scanning image of Acanthamoeba polypha$g a$ cell with fluorescent latex beads (excitation at $520 \mathrm{~nm}$; emission at $540 \mathrm{~nm}$ ). Cells were incubated for $24 \mathrm{~h}$ with 0.5 -mm-diameter fluorescently labeled latex beads, fixed with methanol, and stained with Evans blue. Images were of $0.25-\mathrm{mm}$ optical sections.

other cases, the introduced microorganisms are parasitic and pathogenic for the amoeba and can destroy their host [8]. The most studied model in this situation is that of $L e$ gionella pneumophila, the agent of Legionnaire's disease $[11,12]$. In other instances, the amoebae can maintain symbiotic relationships with introduced microorganisms. Many symbionts of amoebae have been described [13]. In all these situations, the amoebae exert a pressure of selection on the microorganisms that live in their environment and select the microorganisms able to live inside cells. Among their partners are some eukaryotes (Cryptococcus neoformans), bacteria, and, of course, the viruses. This capacity to survive and multiply in amoebae can predispose these microorganisms to survive and multiply in other phagocytic cells, such as human macrophages. We wrote a few years ago that bacteria able to survive in macrophages are usually able to multiply in amoebae and that bacteria able to multiply in the amoebae are able to survive in macrophages [8]. This theorem is confirmed in the majority of the cases. It may also be true for large viruses [14]. This lifestyle of the amoebae is

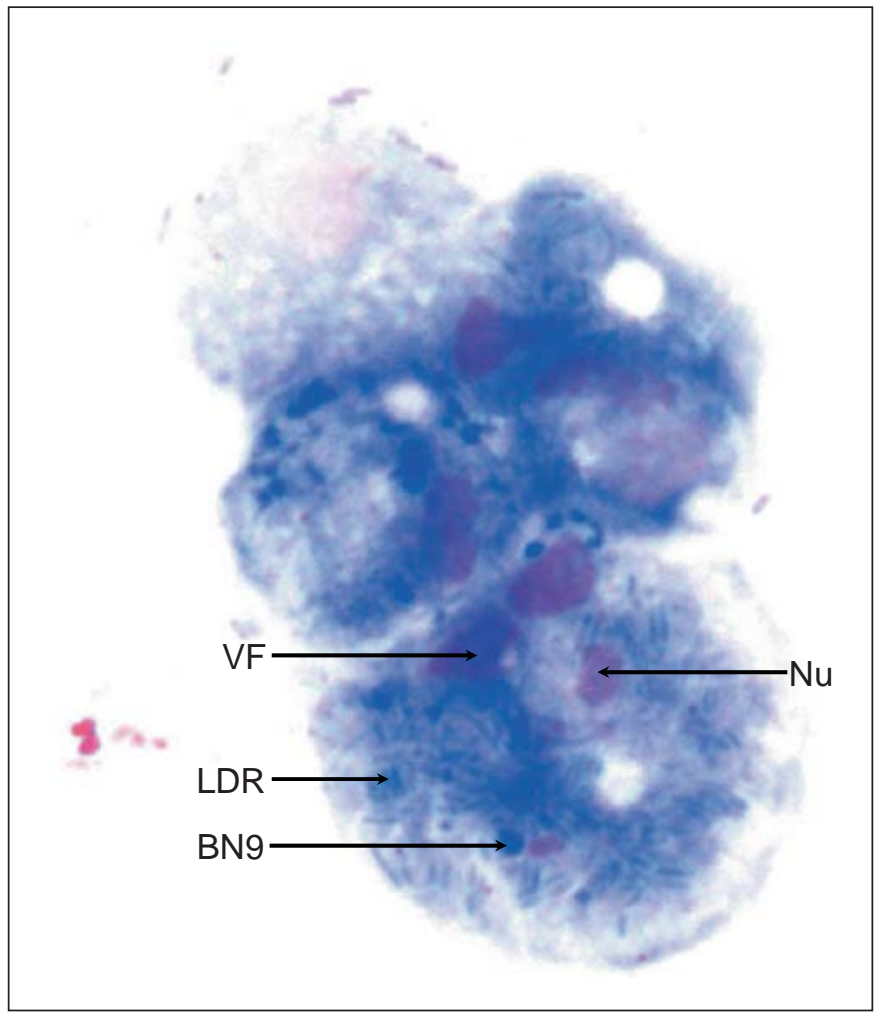

Fig. 2. Amoebae provide an intracellular sympatric environment for viruses and intracellular bacteria to coexist. Infected amoebal cells were observed at 16 and $24 \mathrm{~h}$ p.i. This picture shows Hemacolor (Merck) staining of Acanthamoeba castellanii (nucleus, $\mathrm{Nu}$ ) co-infected with Legionella drancourtii (LDR), Parachlamydia strain BN9 (BN9) and Marseillevirus (virus factory, VF). The $\mathrm{He}-$ macolor-stained microorganisms were controlled by performing amoeba infection with each microorganism alone. Marseillevirus was detected by the characteristic morphology of its VF.

sympatric, i.e. multiple microorganisms live together and thus have the opportunity to exchange genes [15]. The genomic contents of the organism being a balance between the number of laterally acquired genes and the number of lost genes [16], it appears that this capacity of the amoebae to shelter many microorganisms supports the increase in size of the genome of the amoebae and of their various partners [15].

\section{Amoebae and Their Genomes}

Lateral gene transfer in eukaryotes was considered rare in the pre-genomic era [17]. Phagocytic protists, such as amoeba and parabasalids that feed on bacteria, have 
Fig. 3. Range of viral, bacterial, archaeal and eukaryotic genome sizes as currently known. Underlined bold names correspond either to amoebal organisms or to intra-amoebal microorganisms. This figure illustrates that amoebae have the largest genome size among Eukaryota and that obligate intra-amoebal parasites exhibit so far the largest genomes among viruses and obligate intracellular bacteria.

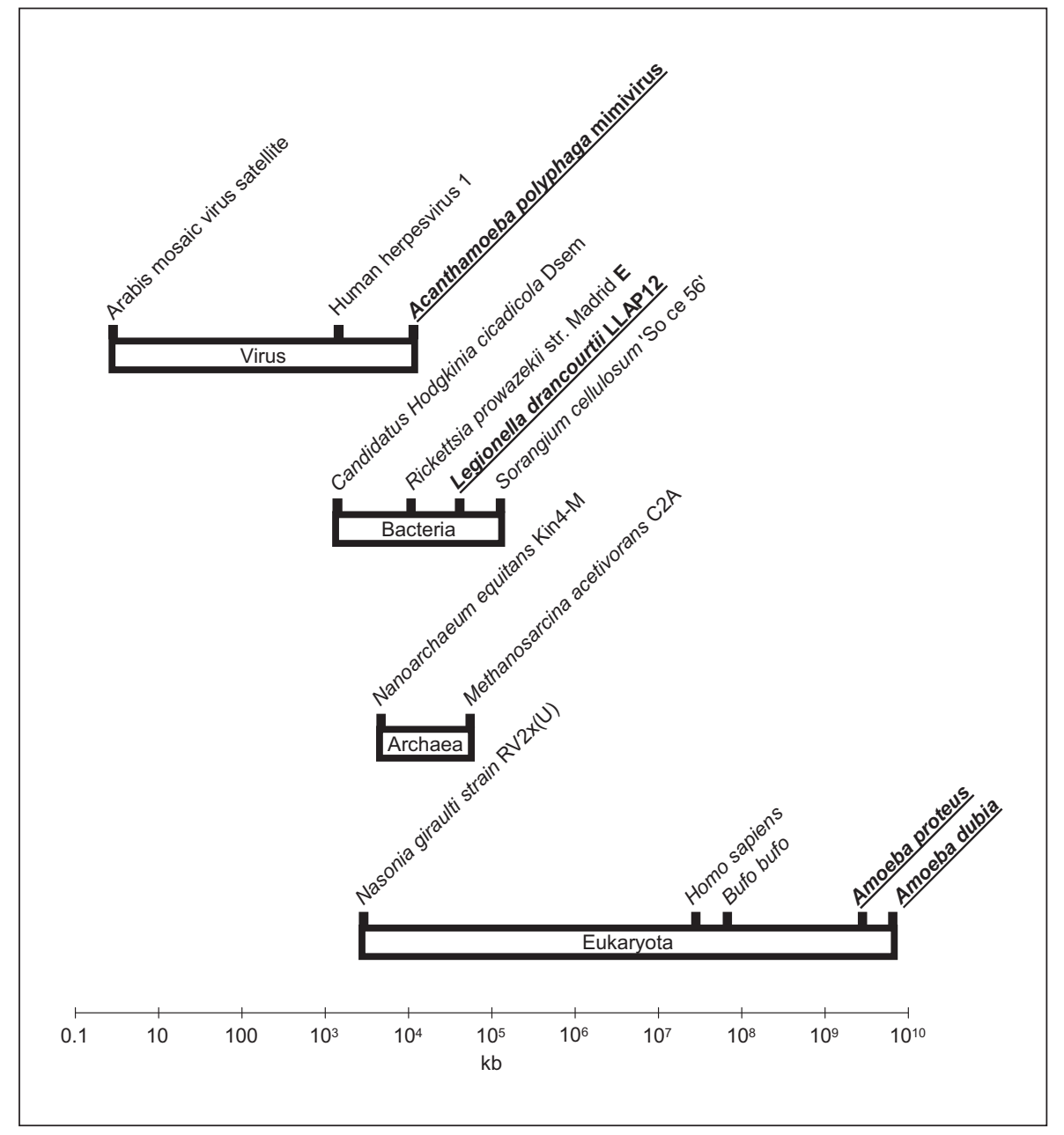

now been found to harbor significantly more genes transferred from bacteria than other eukaryotes. Recently, we found that the malate synthase gene was transferred from bacteria to amoebae (and may have been retransferred to Legionella drancourtii) [18]. This finding favors the 'you are what you eat' hypothesis $[19,20]$. Interestingly, larger phagocytic eukaryotes, such as ciliates and dinoflagellates that also feed on eukaryotic cells, exhibit significantly more identified intra-eukaryotic gene transfer [17]. Finally, it appears that amoebae and other phagocytic protist genomes exhibit more laterally transferred genes of interdomain and intradomain origin, resulting in larger genomes than other eukaryotes. As a matter of fact, Amoeba dubia has a 670,000-Mb genome (200 times bigger than that of human beings with 2,900 Mb) and has the largest known genome of any living organisms (fig. 3) [21].

Amoebae as Genitors and Reservoirs of Giant Viruses

\section{Bacteria Associated with Amoebae}

We recently carried out a review of the genomes of bacteria associated with amoebae [15]. In this work, we highlighted that intracellular bacteria living in amoebae had a significantly larger genome than their phylogenetically close relatives that did not live in amoebae. Thus, $L$. pneumophila, which spends an important part of its life in amoebae, has a genome of $3.4 \mathrm{Mb}$, and its neighbors, Coxiella burnetii and Francisella tularensis (which have the capacity to survive in amoebae but do not multiply with amoebae as the principal host), have a genome of less than $2 \mathrm{Mb}$. L. drancourtii, a strict intra-amoebal Legionella species, has a 4.1-Mb genome [15].

In addition, Chlamydia infecting multicellular organisms have been regarded as paradigmatic bacteria with small genomes (fig. 4). Two Chlamydia spp. from amoebae were sequenced, and both had a genome size double 


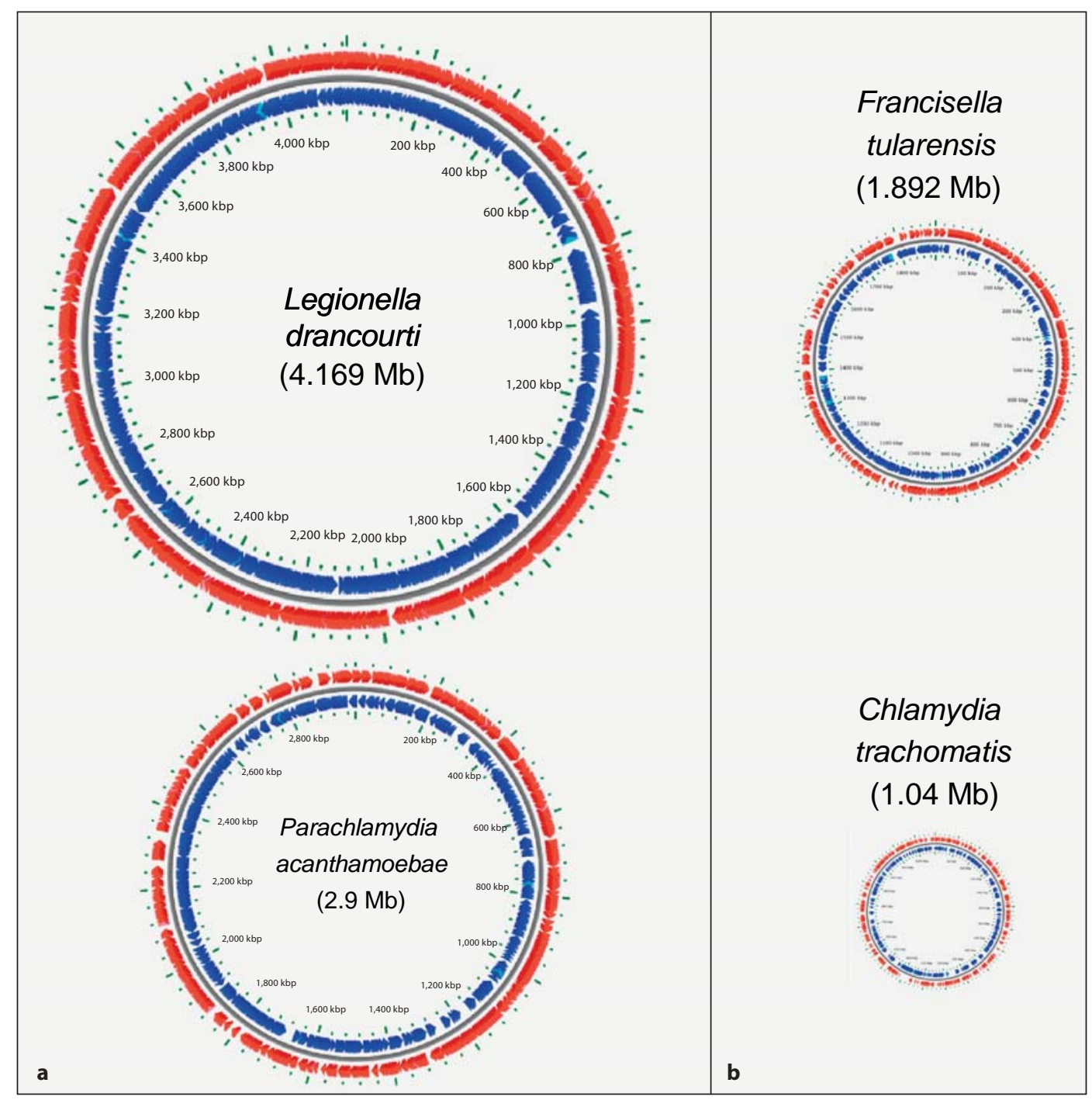

Fig. 4. The larger genome size of sympatric intra-amoebal parasites (a) in comparison with related allopatric intracellular bacteria (b). Predicted protein-coding genes oriented in forward (red) or reverse (blue) strands in genomes of allopatric intracellular bacteria were arbitrarily positioned in genomes of intraamoebal parasites because only non-annotated draft genomes were available.

that of the Chlamydia spp. infecting multicellular organisms $[22,23]$. Indeed, we showed that association with other microorganisms in cells was linked to an increase in the size of the genome [15]. This came to contradict the general theory of reduction of the genome of intracellular bacteria that one observes in general [16]. Finally, intracellular bacteria living in amoebae have a larger genome than other intracellular bacteria (fig. 4). We highlighted that, in contrast, the bacteria living in human lice, which have an allopatric lifestyle (they are usually sterile and, as a consequence, meet few microorganisms), have a de- creased genome size compared to their closest neighbors. Thus, regarding louse parasites, Rickettsia prowazekii has a genome smaller than that of Rickettsia conorii, which lives in ticks [24], Borrelia recurrentis [25] has a smaller genome than that of Borrelia duttonii, which lives in ticks, and Bartonella quintana has a smaller genome than that of Bartonella henselae, which lives in fleas and cats [26]. Thus, in this work, bacteria living in amoebae have a larger genome because of their sympatric lifestyle (several microorganisms can infect the amoeba at the same time). They contain more laterally transferred genes than 
bacteria living an allopatric lifestyle, which are much more homogeneous genetically and include fewer exogenic genes. Among the major elements that one finds transferred between the bacteria living in amoebae is the type IV secretion system $[15,27,28]$. This secretion system is commonly found in amoebal pathogens and allows communication between the bacterium and its amoebic host. In the same way, proteins comprising ankyrin repeats, which make it possible to develop interactions between bacteria and their host, allowing control of amoebal machinery [15], are commonly found in intra-amoebal bacterial pathogens. Interestingly, Mimivirus also has many genes encoding ankyrin repeats [27]. Thus, one could speculate that intracellular microorganisms living in amoebae with others, allowing gene exchanges, can create species with new repertoires. We assumed that most of the current intracellular pathogenic microorganisms had an ancestor selected in a phagocytic protist [28].

\section{Viruses}

It was while seeking to identify a Legionella-like agent of pneumonias that Rowbotham found an atypical Grampositive bacterium that did not cultivate in axenic medium, which proved to be Mimivirus [1]. The history of this discovery is now well known [29]. At the beginning of its history, Mimivirus was considered by some to be an exception, being discovered by chance. Actually, this kind of giant virus in phagocytic protists had been largely ignored. The initiation of a systematic strategy in the search for giant viruses in our laboratory makes it possible to show that amoeba viruses are relatively common $[6,7]$. In addition, one can find many sequences very close to Mimivirus in the metagenomic databanks that contain genes from organisms greater than $0.5 \mu \mathrm{m}$ in size [30]. Indeed, in viral metagenomic studies, particles the size of Mimivirus are not selected. The existence of these giant viruses calls into question the idea of the exhaustiveness of the viral metagenomic studies based on filtration because the giant viruses are retained in the filters [31]. Interestingly, it is noticeable that viruses from phagocytic protists exhibit a significantly larger size and larger genome than those from other eukaryotes (fig. 5).

The discovery of Mimivirus generated many works. Among those studies, some tried to identify the sources of the genomic repertoire of Mimivirus. In addition to the genes that are common to the majority of the nucleocytoplasmic large DNA viruses (NCLDV), Mimivirus $[19,32]$ has many genes that carry the trace of a recent

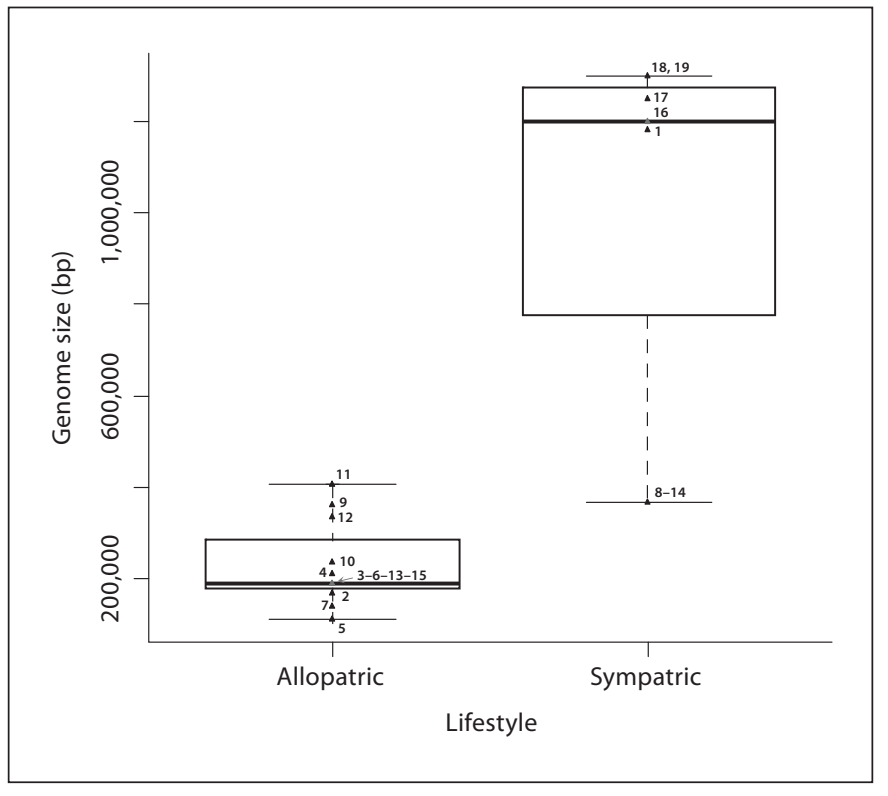

Fig. 5. Box-plot was applied to determine differences in genomic and ecological variables between different NCLDV lineages. Sympatric viruses correspond to viruses which were reported to be ingested by phagocytic protists and could therefore co-exist intracellularly with other microorganisms, whereas this is not the case for allopatric viruses. Virus lifestyle and genome size were significantly correlated (Kruskal-Wallis $\chi^{2}, \mathrm{p}$ value $=0.0007193$ ). 1 = Acanthamoeba polyphaga mimivirus; 2 = African swine fever virus; 3 = Aedes taeniorhynchus iridescent virus; 4 = Invertebrate iridescent virus 6; 5 = Infectious spleen and kidney necrosis virus; 6 = Lymphocystis disease virus - isolate China; 7 = Singapore grouper iridovirus; $8=$ Marseillevirus; $9=$ Canarypox virus; $10=$ Melanoplus sanguinipes entomopoxvirus; 11 = Emiliania huxleyi virus $86 ; 12$ = Ectocarpus siliculosus virus $1 ; 13=$ Ostreococcus tauri virus 1; 14 = Paramecium bursaria Chlorella virus NY-2A; $15=$ Heliothis virescens ascovirus $3 \mathrm{e} ; 16=$ Moumou; $17=$ Courdo11; $18=$ Terra1; 19 = Terra2. Moumou, Courdo11, Terra1 and Terra2 were giant viruses described in La Scola et al. [pp 344-353, in this issue]. Statistical tests were conducted using R language.

transfer from other organisms. On the one hand, it borrowed some genes from eukaryotic hosts [33], but it appears to have mostly imported genes of bacterial origin $[19,32]$. This should not come as a surprise, as Mimivirus cohabitates with many bacteria in the amoeba. We have completed a work [unpubl. data] that shows probable interactions between the bacteria and Mimivirus within Acanthamoeba polyphaga, which influences the speed of their respective growth. Marseillevirus, another giant virus, though smaller, was recently identified. Its analysis showed the chimeric nature of its genome, with genes coming from not only Mimivirus, but also from bacteria, 


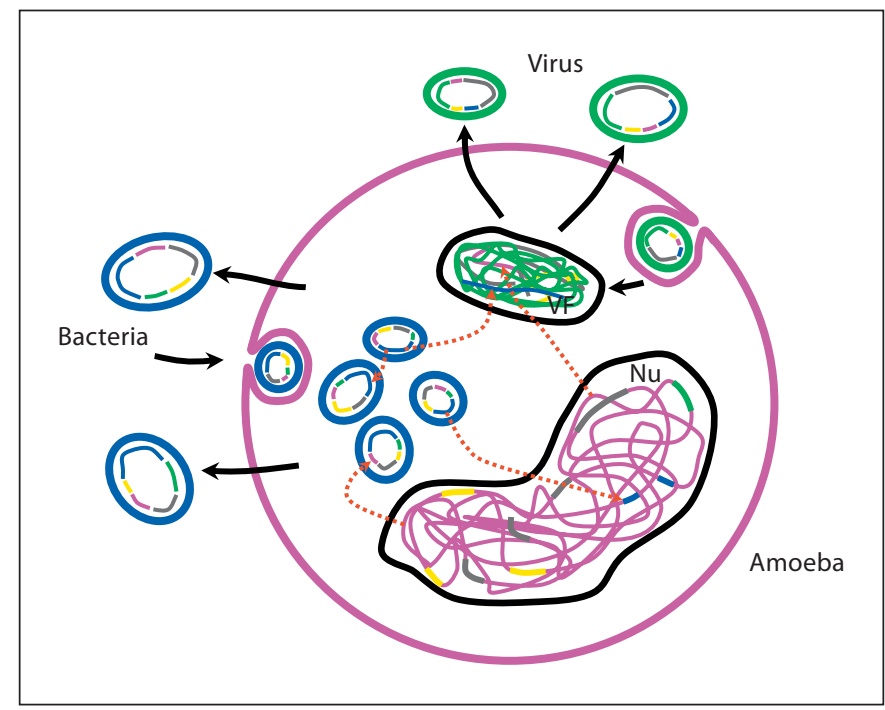

Fig. 6. The amoebal genetic melting pot produces organisms with chimeric genomes. This schematic representation depicts multiple intracellular microorganisms infecting an amoeba. Genomes of each organism are represented with multiple fragments colored according their origins: eukaryote (pink), virus (green), bacteria (blue), archaea (yellow). Lateral gene exchange (dashed red arrows) could occur during microorganism multiplication making the amoeba an appropriate host for gene mixing between the eukaryotic host, its various viruses, and bacterial parasites and symbionts. $\mathrm{Nu}=$ Nucleus; $\mathrm{VF}=$ virus factory.

archaea and eukaryotes [6]. This phenomenon is the same as that observed in the intracellular symbionts of amoebae, such as $L$. drancourtii, which contains a sterol reductase gene of amoebal origin [19,34]. The mode of transfer of these genes remains to be determined. However, it is interesting to note that in a model of infection by poxviruses it was possible to replicate plasmids in the virus factory generated by these poxviruses [35]. In addition, by isolating a second Mimiviridae (Mamavirus), we observed a parasitic virus of Mimivirus that behaves like a bacteriophage does with bacteria, which we thus described as a 'virophage'. The first strain of virophage was called Sputnik $[3,36,37]$. The analysis of the virophage showed evidence of gene transfer between viruses. Indeed, Sputnik contains genes whose origin is entirely viral, with genes from viruses of eukaryotes (such as Mimivirus), bacteriophages, and archaeal viruses. We have not been able to actually determine the role that the virophage plays in gene transfer between the various viruses of amoebae. However, the chimeric composition of genes obtained from other viruses parasitizing organisms of

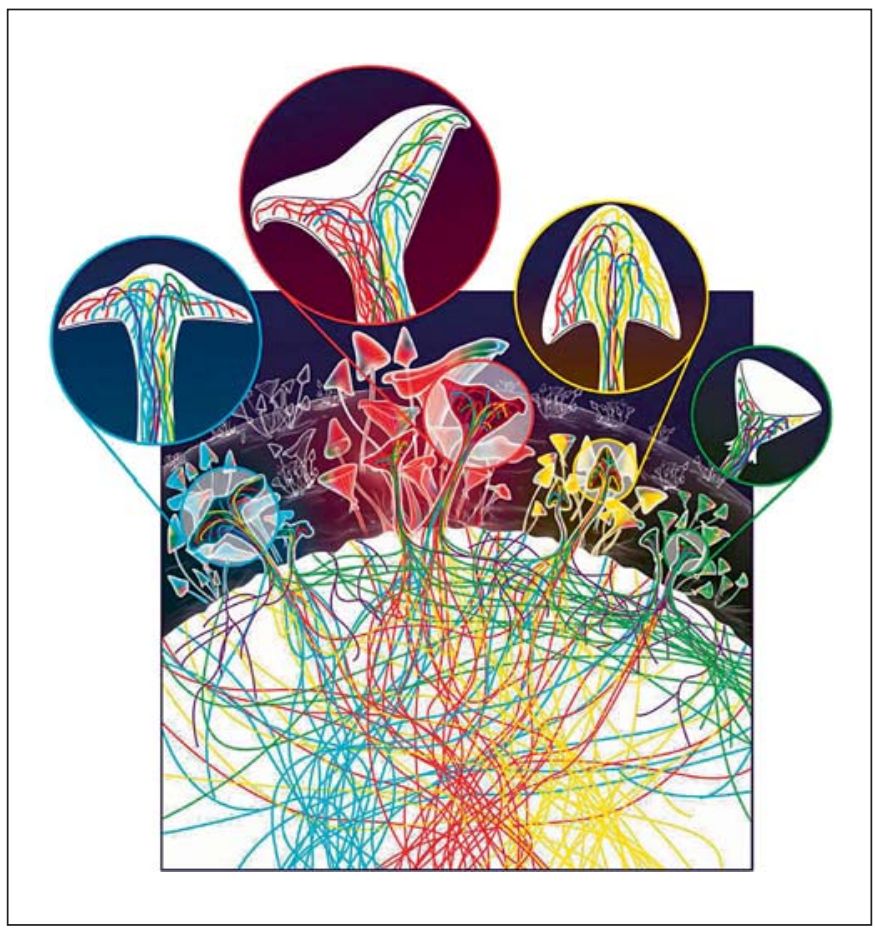

Fig. 7. Rhizome of life. Roots of genes of living species are shown according to current classification of organisms: eukaryotes (red), bacteria (blue), viruses (green), archaea (yellow). In purple are genes without identified origin (ORFans). At the surface, in form of mushrooms, are the current species, containing mixtures of genes of different origin. The color of the mushroom envelope is determined by the origin of the core genome of the species. From [37]. (C) 2010 Elsevier. Reproduced with permission.

the three domains of life (Eukaryota, Archaea and Bacteria) show the existence of lateral gene transfer between viruses of very distant lineages.

\section{The Amoeba as a Melting Pot for the Creation of Species}

The amoeba, with its very large genome and its multiple partners, constitutes a melting pot with the ability to create chimeric species. Indeed, the permanent exchange of genes between microorganisms that have the competence to survive and multiply inside the amoebae can constitute a permanent source of new microorganisms with original repertoires (fig. 6). The environmental conditions will then select the species that have the capacity to multiply, while the others will be eliminated. This 


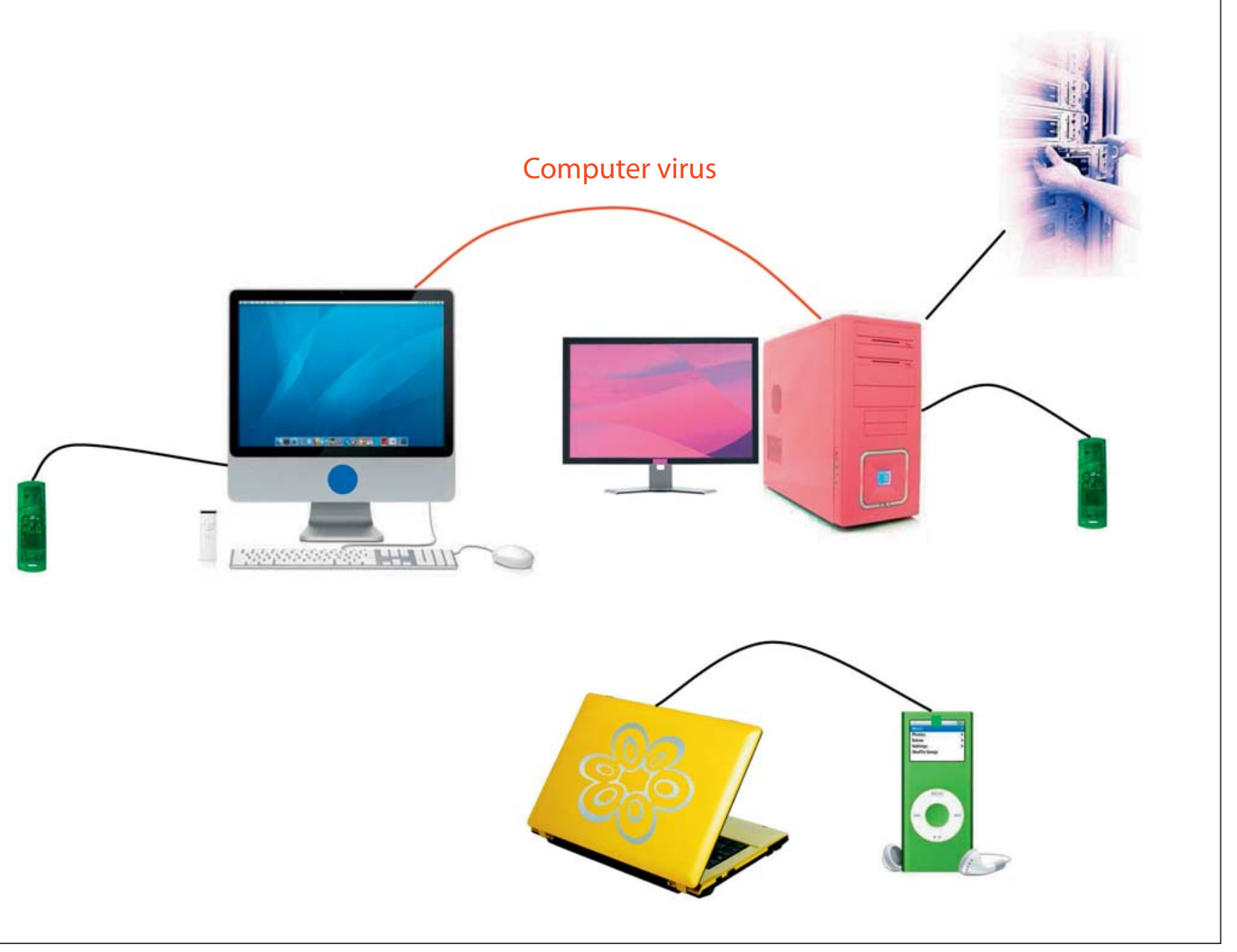

Fig. 8. Genetic exchanges between ribosome-encoding organisms and capsid-encoding organisms could be comparable to information transmission in computer network. Capsid-encoding organisms could exchange genetic information with ribosome-encoding organisms and could be regarded as a USB flash drive (or oth- er external computer devices) which stores information and transfers it between computers. Selfish genetic elements could be similar to computer viruses able to parasitize both computers and USB flash drives (or other external computer devices). particular creativity of the phagocytic protists is probably a major element of renewal of the microbial species on the surface of the earth. The transfer of genes and the creation of new species are two elements that very strongly challenge the notion of such a tree of life, as that proposed by Darwin [37]. Genomics has deeply modified our perception of the living world. It is clear that the current living organisms are chimeras and that two of the major elements of the Darwinian theory, the purely vertical genealogy inherited from the parents and the absence of jumps in the evolution, are deeply contradicted [38]. Multiple origins of gene repertoires currently make it impos- sible to represent the genealogy of living things in the form of trees. Indeed, each gene can have a different history; sometimes, even the various parts of genes (because of homologous recombination) have different histories. The representation of species as a bush or a forest does not reflect the reality observed since the rise of genomics [39]. In addition, the representation of a Darwinian tree induces thinking that current species derive from species that diverged since the origin of life. This is not confirmed by genomics because, as in amoebae, species have repertoires resulting from fusions of species with different origins. 


\section{Rhizome of Life}

One of the more striking elements in the genome analysis of eukaryotes is the recently discovered quasi-complete integration of Wolbachia, a symbiont, in nematodes (Brugia malayi), insects and spiders [40]. The integration of this same bacterial species in distinct multicellular organisms of such distant eukaryotes generates chimeras, which constitutes a formal refutal of the evolutionary vision derived from the tree of life [41]. To solve the problem of representing the swarming and fusion of life, we recently proposed using the description by Deleuze and Guattari of social organization by using their term 'rhizome', and we proposed replacing the 'tree of life' with the 'rhizome of life' [42], which shows the multiple roots and tangle of the origins of currently living species (fig. 7) [37]. In addition, this perception of life evolution makes it possible to leave open the possibility of the creation of entirely new repertoires resulting from the fusion of various organisms such as we currently perceive them. On the whole, amoebae are a paradigm of the persistence of the creation of new life forms on earth. The phagocytic capacity of amoebae selects giant viruses, small eukaryotes and bacteria and forces them to live together for some period of time. The phagocytosis of multiple organisms at the same time makes it possible to exchange genes and to create new species by creating completely new repertoires. Finally, one can represent various forms of life, as we proposed recently, by naming the cells that encode the whole ribosome the ribosome-encoding organisms. This includes Eukaryota, Bacteria and Archaea. The viruses encoding a capsid are named capsid-encoding organisms [43]. In this current definition, ribosome-encoding organisms can be regarded as computers not only able to store information but also able to duplicate, and to possibly translate information by printing or by forming images (fig. 8). Capsid-encoding organisms can be regarded as being USB flash drives (or other external computer devices) that contain and store information that, in order to be used, must pass through a computer (ribosome-encoding organisms). Lastly, there exist selfish genetic ele- ments that are able to parasitize either the USB flash drive or the computers and that function similarly to computer viruses. For the moment, these mobile and free genetic elements of selfish gene types are not combined in a stable way in any organism.

\section{Conclusion}

Amoebae, as phagocytic protists, are not very specialized for their intracellular inhabitants. They are a hot spot for gene transfer and genome plasticity. As such, amoebae can exchange genes with ingested microorganisms and facilitate lateral gene transfer between bacteria and between bacteria and viruses. As a consequence of this broadly sympatric lifestyle, amoebae harbor very large genomes compared to other eukaryotes and select and/or promote intracellular bacteria with large genome repertoires as well as giant viruses. In contrast, lice are extremely specialized and have an extremely allopatric lifestyle. These organisms represent two extreme lifestyles with extreme genome sizes. As a consequence, lice have the smallest genome size among all tested insects [44]; lice symbionts have a small genome size, and the bacteria transmitted by human lice also have a small genome. In these examples, lifestyle (sympatric or allopatric) is associated with the genome size of their associated microorganisms, either large (sympatric amoeba) or small (allopatric lice). Finally, amoebae, intracellular bacteria of amoebae, and viruses of amoebae all have significantly larger repertoires than other related organisms (fig. 3). This favors the hypothesis of a continuous creation in phagocytic protists of new genomic repertoires leading to new species, of which some will be able to specialize later in eukaryotic pathogens.

\section{Acknowledgments}

We would like to thank Leon Espinosa and Sylvain Buffet for technical help with the figures.

\section{References}

1 La Scola B, Audic S, Robert C, Jungang L, de Lamballerie X, Drancourt M, Birtles R, Claverie JM, Raoult D: A giant virus in amoebae. Science 2003;299:2033.

2 Raoult D, Audic S, Robert C, Abergel C, Renesto P, Ogata H, La SB, Suzan M, Claverie JM: The 1.2-megabase genome sequence of Mimivirus. Science 2004;306:1344-1350.
- 3 La Scola B, Desnues C, Pagnier I, Robert C, Barrassi L, Fournous G, Merchat M, SuzanMonti M, Forterre P, Koonin E, Raoult D: The virophage as a unique parasite of the giant mimivirus. Nature 2008;455:100-104.

4 Raoult D: The journey from Rickettsia to Mimivirus. ASM News 2005;71:278-284. 
5 Sun S, La Scola B, Bowman VD, Ryan MR, Whitelegge JP, Raoult D, Rossmann MG: Structural studies of the Sputnik virophage. Mol Cell 2009, in press.

6 Boyer M, Yutin N, Pagnier I, Barrassi L, Fournous G, Espinosa L, Robert C, Azza S, Sun S, Rossmann MG, Suzan-Monti M, La Scola B, Koonin E, Raoult D: Giant Marseillevirus highlights the role of amoebae as a melting pot in emergence of chimaeric microorganisms. Proc Nat Acad Sci USA 2009; 106:21848-21853.

7 La Scola B, Campocasso A, Fournous G, N'Dong R, Barrassi L, Fauldraut C, Raoult D: Tentative characterization of new environmental giant viruses by MALDI-TOF mass spectrometry. Intervirology 2010,53:98-107.

8 Greub G, Raoult D: Microorganism resistant to free-living amoebae. Clin Microbiol Rev 2004; 17:413-433.

$\checkmark 9$ Audic S, Robert C, Campagna B, Parinello H, Claverie JM, Raoult D, Drancourt M: Genome analysis of Minibacterium massiliensis highlights the convergent evolution of waterliving bacteria. PLoS Genet 2007;3:e138.

10 Cavalier-Smith T: The phagotrophic origin of eukaryotes and phylogenetic classification of Protozoa. Int J Syst Evol Microbiol 2002;52:297-354.

11 Swanson MS, Hammer BK: Legionella pneumophila pathogesesis: a fateful journey from amoebae to macrophages. Annu Rev Microbiol 2000;54:567-613.

12 Rowbotham TJ: Preliminary report on the pathogenicity of Legionella pneumophila for freshwater and soil amoebae. J Clin Pathol 1980;33:1179-1183.

13 Schmitz-Esser S, Toenshoff ER, Haider S, Heinz E, Hoenninger VM, Wagner M, Horn M: Diversity of bacterial endosymbionts of environmental Acanthamoeba isolates. Appl Environ Microbiol 2008;74:5822-5831.

14 Ghigo E, Kartenbeck J, Lien P, Pelkmans L, Capo C, Mege JL, Raoult D: Amoebal pathogen Mimivirus infects macrophages through phagocytosis. PLoS Pathog 2008;4:e1000087.

15 Moliner C, Fournier PE, Raoult D: Genome analysis of microorganisms living in amoebae reveals a melting pot of evolution. FEMS Microbiol Rev 2009, in press.

-16 Merhej V, Royer-Carenzi M, Pontarotti P, Raoult D: Massive comparative genomic analysis reveals convergent evolution of specialized bacteria. Biol Direct 2009;4:13.

$\checkmark 17$ Andersson JO: Lateral gene transfer in eukaryotes. Cell Mol Life Sci 2005;62:11821197.
18 Moliner C, Raoult D, Fournier PE: Evidence of horizontal gene transfer between amoeba and bacteria. Clin Microbiol Infect 2009, Epub ahead of print.

19 Filee J, Siguier P, Chandler M: I am what I eat and I eat what I am: acquisition of bacterial genes by giant viruses. Trends Genet 2007; 23:10-15.

20 Doolittle WF: You are what you eat: a gene transfer ratchet could account for bacterial genes in eukaryotic nuclear genomes. Trends Genet 1998;14:307-311.

21 Parfrey LW, Lahr DJ, Katz LA: The dynamic nature of eukaryotic genomes. Mol Biol Evol 2008;25:787-794.

22 Horn M, Collingro A, Schmitz-Esser S, Beier CL, Purkhold U, Fartmann B, Brandt P, Nyakatura GJ, Droege M, Frishman D, Rattei $\mathrm{T}$, Mewes HW, Wagner M: Illuminating the evolutionary history of chlamydiae. Science 2004;304:728-730.

23 Greub G, Kebbi-Beghdadi C, Bertelli C, Collyn F, Riederer BM, Yirsin C, Croxatto A, Raoult D: High throughput sequencing and proteomics to identify immunogenic proteins of a new pathogen: the dirty genome approach. PLoS One 2009; 4:e8423.

24 Ogata H, Audic S, Renesto-Audiffren P, Fournier PE, Barbe V, Samson D, Roux V, Cossart P, Weissenbach J, Claverie JM, Raoult D: Mechanisms of evolution in Rickettsia conorii and $R$. prowazekii. Science 2001;293:2093-2098.

25 Lescot M, Audic S, Robert C, Nguyen TT, Blanc G, Cutler SJ, Wincker P, Couloux A, Claverie JM, Raoult D, Drancourt M: The genome of Borrelia recurrentis, the agent of deadly louse-borne relapsing fever, is a degraded subset of tick-borne Borrelia duttonii. PLoS Genet 2008;4:e1000185.

26 Alsmark CM, Frank AC, Karlberg EO, Legault BA, Ardell DH, Canback B, Eriksson AS, Naslund AK, Handley SA, Huvet M, La Scola B, Holmberg M, Andersson SG: The louse-borne human pathogen Bartonella quintana is a genomic derivative of the zoonotic agent Bartonella henselae. Proc Natl Acad Sci USA 2004;101:9716-9721.

27 Ogata H, Robert C, Audic S, Robineau S, Blanc G, Fournier PE, Renesto P, Claverie JM, Raoult D: Rickettsia felis, from culture to genome sequencing. Ann NY Acad Sci 2005; 1063:26-34.

-28 Ogata H, La SB, Audic S, Renesto P, Blanc G, Robert C, Fournier PE, Claverie JM, Raoult D: Genome sequence of Rickettsia bellii illuminates the role of amoebae in gene exchanges between intracellular pathogens. PLoS Genet 2006;2:e76.
29 Raoult D, La SB, Birtles R: The discovery and characterization of Mimivirus, the largest known virus and putative pneumonia agent. Clin Infect Dis 2007;45:95-102.

30 Claverie JM, Abergel C: Mimivirus and its virophage. Annu Rev Genet 2009;43:49-66.

- 31 Rodriguez-Valera F, Martin-Cuadrado AB, Rodriguez-Brito B, Pasic L, Thingstad TF, Rohwer F, Mira A: Explaining microbial population genomics through phage predation. Nat Rev Microbiol 2009;7:828-836.

- 32 Moreira D, Brochier-Armanet C: Giant viruses, giant chimeras: the multiple evolutionary histories of Mimivirus genes. BMC Evol Biol 2008;8:12.

33 Moreira D, Lopez-Garcia P: Comment on 'The 1.2-Megabase genome sequence of Mimivirus'. Science 2005;308:1114a.

-34 Moliner C, Raoult D, Fournier PE: Evidence that the intra-amoebal Legionella drancourtii acquired a sterol reductase gene from eukaryotes. BMC Res Notes 2009;2:51.

35 De Silva FS, Moss B: Origin-independent plasmid replication occurs in vaccinia virus cytoplasmic factories and requires all five known poxvirus replication factors. Virol J 2005;2:23.

36 Desnues C, Raoult D: Inside the morphology of the virophage infection. Intervirology 2009 , in press.

37 Raoult D: The post-Darwinist rhizome of life. Lancet 2009;375:104-105.

38 Darwin C: On the Origin of Species. New York, Harward College Library, 1859.

39 Koonin EV, Wolf YI: The fundamental units, processes and patterns of evolution, and the tree of life conundrum. Biol Direct 2009;4: 33.

40 Callaway E: Genomes within genomes. Nature 2007;449:6.

41 Doolittle WF, Bapteste E: Pattern pluralism and the Tree of Life hypothesis. Proc Natl Acad Sci USA 2007;104:2043-2049.

42 Deleuze G, Guattari F: Rhizome: introduction. Paris, Éditions de Minuit, 1976.

43 Raoult D, Forterre P: Redefining viruses: lessons from Mimivirus. Nat Rev Microbiol 2008;6:315-319.

44 Pittendrigh BR, Clark JM, Johnston JS, Lee $\mathrm{SH}$, Romero-Severson J, Dasch GA: Sequencing of a new target genome: the Pediculus humanus humanus (Phthiraptera: Pediculidae) genome project. J Med Entomol 2006; 43:1103-1111. 